\title{
Oxyhemoglobin to Total Hemoglobin Ratio Measurement
}

National Cancer Institute

\section{Source}

National Cancer Institute. Oxyhemoglobin to Total Hemoglobin Ratio Measurement. NCI Thesaurus. Code C147359.

The determination of the ratio of oxyhemog lobin compared to total hemoglobin present in a sample. The measurement may be expressed as a ratio or percentage. 